\title{
Mathematical and physical modeling of heat transfer through window with heat-reflecting screens to determine the potential of reducing thermal costs for microclimate parameters maintaining
}

\author{
Nikolay Smirnov ${ }^{1, *}$, Vladimir Tyutikov ${ }^{1}$, and Vadim Zakharov ${ }^{1}$ \\ ${ }^{1}$ Ivanovo State Power Engineering University, Heat Power Engineering Department, 153003 Ivanovo, \\ Russia
}

\begin{abstract}
A mathematical model describing the process of heat transfer through windows with heat-reflecting screens, taking into account physical and geometrical parameters of the building construction, was developed. The computer program for the calculation of heat transfer through the window has been developed and results of numerical heat transfer simulation for different parameters of indoor and outdoor air are given. Expressions to determine the thermal resistance for the specific types of glazing with a heat-reflecting screens installed outside were derived on the basis of the developed method. The adequacy of the suggested mathematical model was confirmed by experimental data.
\end{abstract}

\section{Introduction}

Pursuant to Russian legislation, annual specific consumption of energy in buildings as of 1 January 2020 shall be reduced by $40 \%$ of the basic level.

Among the costs of fuel and energy resources at an industrial enterprise, the cost of maintaining the necessary parameters of the microclimate is from $10 \%$ (the oil refinery, chemical industry) to $40-50 \%$ (machine-building, electrotechnical enterprises) [1]. According to the data of the Central Research Institute of Housing [2] a significant proportion of heat loss in residential buildings falls on windows. So, for 5-storey residential buildings (series 1-511 and 1-447) the thermal transmission losses through the windows make up from 46 to $54 \%$. European Union legislatures stipulate a coefficient of heat transfer resistance for windows by 2020 of $1.67-2.0 \mathrm{~m}^{2 \circ} \mathrm{C} / \mathrm{W}$, while Russian official bodies stipulate $1.0-1.05 \mathrm{~m}^{2 \circ} \mathrm{C} / \mathrm{W}$ by 2016 . Therefore, the development of new windows with increased heat-shielding properties is an actual task.

The scientists from Ivanovo State Power Engineering University (ISPU) and National Institute of Applied Sciences in Strasbourg (INSA de Strasbourg) developed [3] and patented window designs with panel, roll and blinds type heat-reflecting screens, which are

Corresponding author: nsmirnov@bk.ru 
made of metal and significantly reduce heat losses. Screens can be positioned indoors, outdoors or in a space between glass panes. The use of screens is desirable during nighttime or in the absence of people. Screens may be placed inside or outside buildings, or between window panes.

An example of outside panel heat-reflecting screen installation in the window (position 3 ) in room, where the maintenance of the necessary microclimate parameters is carried out with the help of an air conditioning system, is shown in Fig. 1.

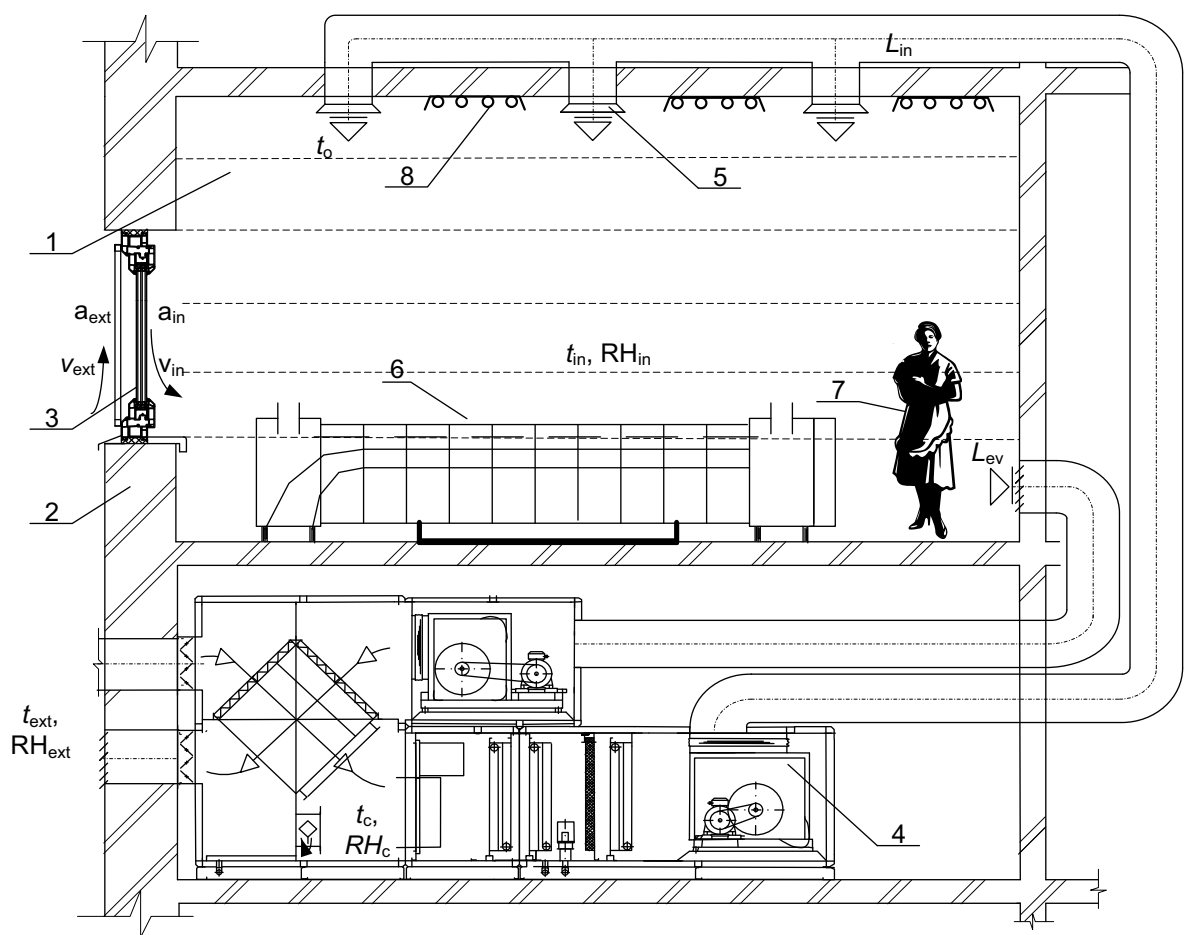

Fig. 1. System for maintaining of technological microclimate for buildings with adjustable resistance windows: 1 - production room; 2 - wall; 3 - a window with a panel-type heat-reflecting screen installed outside; 4 - the conditioner; 5 - air distributor; 6 - production equipment; 7 - staff; 8 lighting fixtures.

The use of screens not only reduces losses related to heat transfer but also permits ambient temperature reduction in setback heating mode [3].

It is necessary to know the actual resistance to heat transfer of windows with heatreflecting screens for calculating the real savings of thermal energy for the compensation of transmission losses.

\section{Development and software implementation of mathematical model of heat transfer through a window with screens}

A computational scheme was developed for the model describing the process of heat transfer through the translucent part of the window using heat-reflecting screens. The mathematical model of heat exchange through the window system with screens is considered as a multi-layer inertialless system consisting of glazing layers, metal screens and air gaps. Each layer has its own physico-geometric parameters determined by the 
glazing and screens material, the type of filling of the air gap, the thickness of the layers $(h$, $\left.\delta_{g l}\right)$, etc. On the interfaces between layers, the conditions for equality of temperatures and heat fluxes are specified. In each air gap, as well as on inner and outer surfaces of the structure, there was a coefficient of heat transfer $\alpha_{i(j)}$, which is the sum of convective $\alpha_{i(j)}^{k o n v}$ and radiant $\alpha_{i(j)}^{r a d}$ heat transfer.

$$
\alpha_{i(j)}=\alpha_{i(j)}^{r a d}+\alpha_{i(j)}^{k o n v}
$$

Coefficients of convective and radiant heat exchange were determined by well-known empirical formulas [3].The system of equations was solved numerically in the program Matlab. The developed mathematical model was implemented in the program for calculating of heat transfer process for a glazed unit with metal heat-reflecting screens "Glass + Screens". The results of numerical simulation in the "Glass + Screens" program can be seen in Fig. 2.

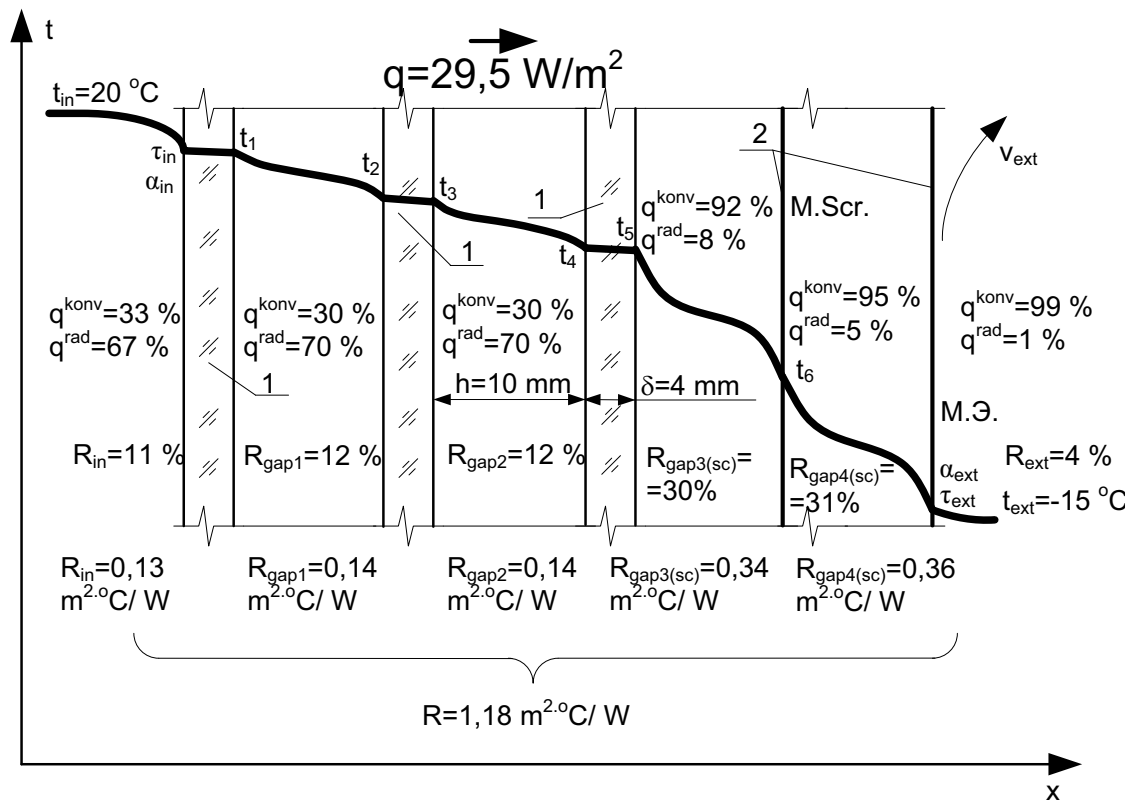

Fig. 2. The results of simulating the process of heat transfer through a triple-glazed window with screens in the developed program: 1 - glass, 2 - aluminum screens.

We used a glass unit (hereinafter G.U.) as $4 \mathrm{M} 1 \times 10 \times 4 \mathrm{M} 1 \times 10 \times 4 \mathrm{M} 1$. At the same distance from each other, $h=10 \mathrm{~mm}$, we simulated the installation of heat-reflecting metal screens (hereinafter M.Scr.), made of polished aluminum. The discrepancy in the calculation of the surface temperatures varied from 0.04 to $0.18^{\circ} \mathrm{C}$ (or 0.1 to $0.5 \%$ ). It should be noted that a significant part of the resistance of this design was given by the thermal resistance of the air gap between the glass and the screen $\left(R_{g a p}=0.34\left(\mathrm{~m} 2{ }^{\circ} \mathrm{C}\right) / \mathrm{W}\right.$ or $30 \%)$ and between the screens $\left(R_{\text {gap }}=0.36\left(\mathrm{~m} 2{ }^{\circ} \mathrm{C}\right) / \mathrm{W}\right.$ or $\left.31 \%\right)$, and in these gaps, because of the high reflectivity of polished aluminum, the radiant heat flux $q^{\text {rad }}$ was only 8 and $5 \%$, respectively.

With the help of regression analysis, after processing the data of the computer program "Glass + Screens", empirical formulas were obtained [3] for calculating the resistance to heat transfer in the middle (central) window zone with heat-reflecting screens. The change 
of the temperature difference between the internal and external air $\Delta t$ was set in the range from 10 to $60{ }^{\circ} \mathrm{C}$ (at $t_{i n}=20^{\circ} \mathrm{C}$ ), the speed $v_{e x t}$ - from 1 to $5 \mathrm{~m} / \mathrm{s}$.

Thus, for a triple-glazed window with the formula $4 \mathrm{M} 1 \times 10 \times 4 \mathrm{M} 1 \times 10 \times 4 \mathrm{M} 1$ and two heat-reflecting screens installed from the outside at a distance of $10 \mathrm{~mm}$ from each other, in case of natural convection at the inner surface, the resistance to heat transfer can be determined by formula

$$
R\left(\Delta t, v_{\text {ext }}\right)=0.889+\frac{14.1}{\Delta t+17.6}+\frac{1}{7.34 \cdot v_{\text {ext }}^{0.656}+3.78 \cdot e^{-1.91 \cdot v_{\text {ext }}},}
$$

where $\Delta t$ - the difference between temperatures of indoor and outdoor air, ${ }^{\circ} \mathrm{C}$;

$v_{\text {ext }}$ - speed of outside air, $\mathrm{m} / \mathrm{s}$.

If the recirculation ventilation unit is operating in a room or the inflow to a room is effected by mechanical ventilation, that is, forced convection is present at an inner surface of window. The resistance to heat transfer of a 2 -screen window can be expressed

$$
R\left(\Delta t, v_{\text {in }}, v_{\text {ext }}\right)=0.749+\frac{1}{9.6+3.8 \cdot v_{\text {in }}}+\frac{14,1}{\Delta t+17.6}+\frac{1}{7.34 \cdot v_{\text {ext }}^{0.656}+3.78 \cdot e^{-1.91 \cdot v_{\text {ext }}}},
$$

where $v_{\text {in }}$ is the air velocity at the inner surface of the window, $\mathrm{m} / \mathrm{s}$.

On the basis of the derived empirical relationships for G.U. with heat-reflecting screens, in the case of natural convection inside, graphs of the dependences of the resistance to heat transfer $R$ from $\Delta t$, vext were obtained (see Fig. 3).

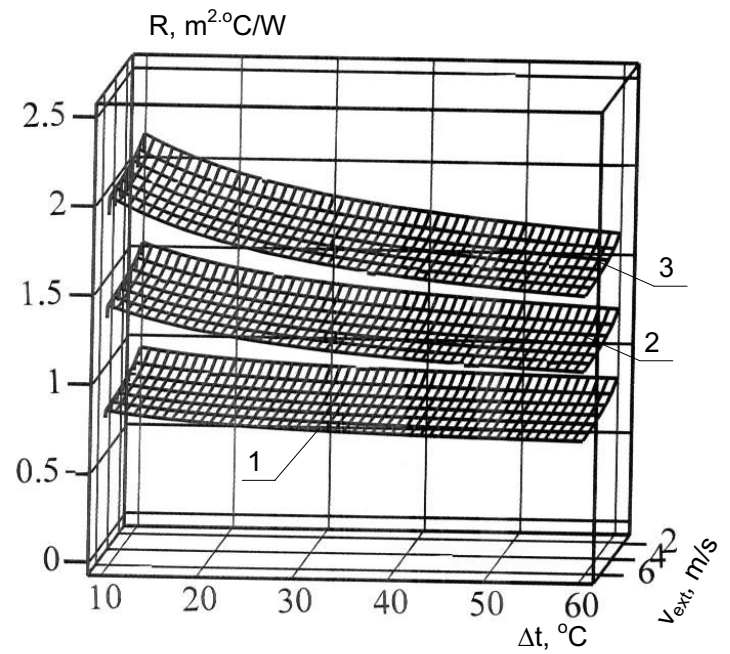

Fig. 3 Dependence of the resistance to heat transfer $R$ of the central zone of window when using the G.U. by the formula $4 \mathrm{M} 1 \mathrm{x} 10 \mathrm{x} 4 \mathrm{M} 1 \mathrm{x} 10 \mathrm{x} 4 \mathrm{M} 1$ and installed outside 1 - one metal screen; 2 - two screens; 3 - three screens.

As can be seen from the simulation data (Fig. 3), the resistance to heat transfer depends more on the temperature difference between the internal and external air. The maximum resistance is obtained with the minimum temperature difference and the minimum speed of the outside air. Thus, the resistance to heat transfer for windows with heat-reflecting screens is a nonlinear dependence. 


\section{Verification of a mathematical model using physical experiment}

For the good verification of the heat transfer model through a window with a heat-reflecting screen, experimental data from a field experiment conducted in a certified climate chamber of Ivanovo Construction Research Center were used. The study was carried out with different variants of the arrangement of heat-reflecting screens relative to the triple-glazed unit. As a control sample we used a triple-glazed window with the formula $4 \mathrm{M} 1 \mathrm{x} 10 \mathrm{x} 4 \mathrm{M} 1 \mathrm{x} 10 \mathrm{x} 4 \mathrm{M} 1$ and aluminum screens. The system carried out 20 measurements of the values for each steady-state regime. Experimental data were processed using mathematical statistics.

The temperature inside the warm compartment of the climatic chamber was maintained at $20-21{ }^{\circ} \mathrm{C}$. Thermograms and temperature graphs along the cutting line of the central part of glass can be seen in Figure 4. Aluminum screens are installed on the left outside at a distance of $10 \mathrm{~mm}$ from the outer glass of the triple-glazed window, to the right - only the glass unit.

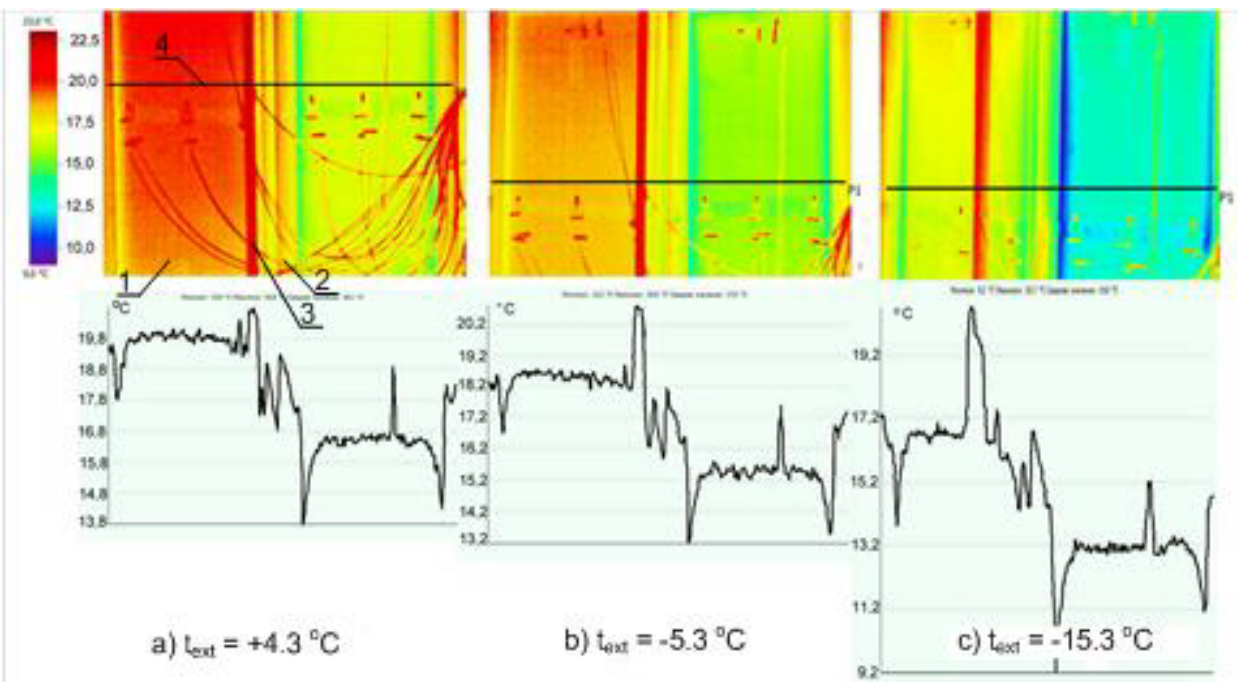

Fig. 4. Thermograms and temperature graphs along the cutting line on the inner surface of the central part of glass unit while keeping the air temperature in the cold compartment of the air chamber equal to $+4.3{ }^{\circ} \mathrm{C}(\mathrm{a}),-5.3{ }^{\circ} \mathrm{C}(\mathrm{b})$ and $-15.3{ }^{\circ} \mathrm{C}(\mathrm{c}): 1$ - the internal surface of the window; 2 - binding from plastic pro-fillet; 3 - a tire for fixing thermocouples measuring; 4 - cutting line.

As expected, the temperatures on the surface of the glass pane are more reduced when the outside air temperature changes in the control version (only the triple-glazed unit). In the zone where the metal screen is installed from the outside, the temperature drop on the inner glass is less when the change is made. Thermograms clearly show the edge zones of the glass unit, where, due to the formation of "cold bridges" due to internal aluminum frames, the surface temperature drops by $2-4{ }^{\circ} \mathrm{C}$ in the control, and by $2-3{ }^{\circ} \mathrm{C}$ in the screen mounting option.

In Fig. 5 a comparison of computer calculation data and values of a physical experiment for the resistance of heat transfer for window with metal screens installed outside $10 \mathrm{~mm}$ apart from each other in the case of a change in the temperature difference between internal and external air is made. The air velocity in the cold compartment of the climatic chamber was maintained within $3 \mathrm{~m} / \mathrm{s}$. 
As can be seen from Fig. 5, the experimental values of the resistance to heat transfer is occupied in the confidence interval of mathematical modeling data obtained from empirical formulas. The data of the physical experiment also support the hypothesis that the resistance to heat transfer of a window with heat-reflecting screens is not a constant (without taking into account the correction for speed), as in the case of using only a tripleglazed unit, but depends on the difference between the temperatures of internal and external air.

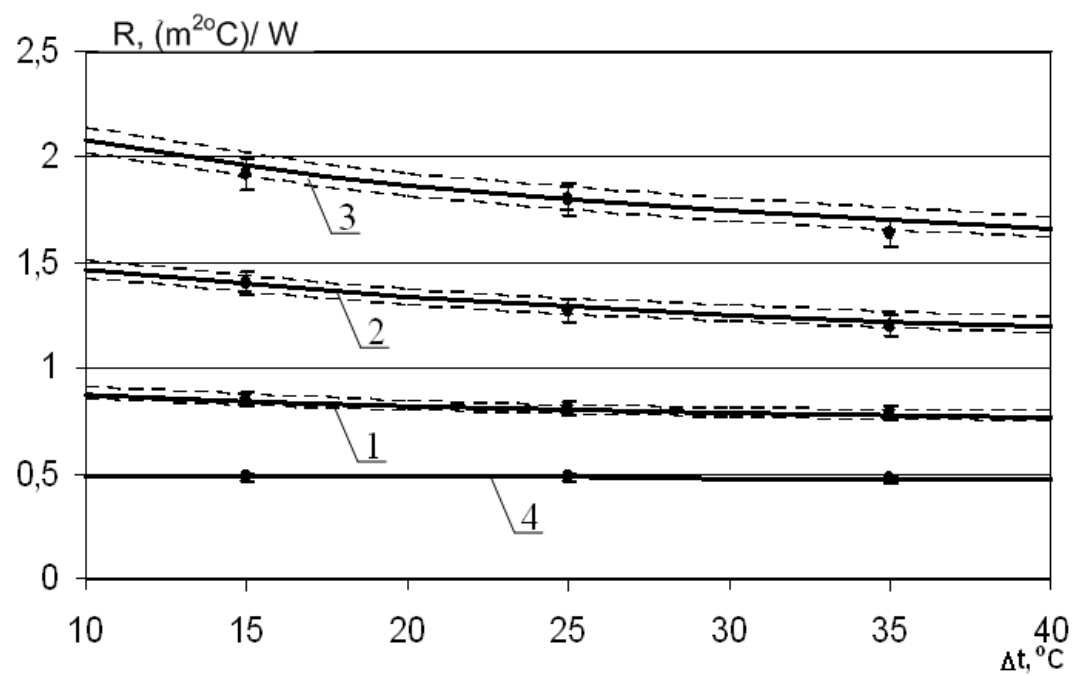

Fig. 5. Comparison of the experimental and calculated values of the resistance to heat transfer of the central zone of window, depending on the difference between the temperatures of internal and external air for: 1 - G.U. and 1 M.Scr.; 2 - G.U. and 2 M.Scr.; 3 - G.U. and 3 M.Scr.; 4 - G.U. (control). Solid line - the results of calculation by empirical formulas; dashed lines - the boundaries of the confidence interval due to the relative error of the mathematical model $\pm 3 \%$; points are experimental values with a relative error of measurement $\pm 4 \%$.

\section{Conclusion}

The results of these studies can be used to determine the potential for using heat-reflecting screens in windows for systems of intermittent heating of buildings, including the case of applying the technology of preliminary air drying for wet or normal conditions of premises of industrial enterprises.

\section{References}

1. A.V. Sinilova, Russian foreign economic bulletin, 10 (2012)

2. V.S. Belyaev, S.K. Esengabulov, Building physics in the XXI-st century (NIISF RAASN, Moscow, 2006)

3. N.N. Smirnov, B. Flaman, M. Barba, V.M. Zakharov, V.V. Tyutikov, D.A. Lapateev, Vestnik of Ivanovo State Power Engineering University, 2 (2015) 